\title{
A derived and validated score to predict prolonged mechanical ventilation in patients undergoing cardiac surgery
}

\author{
Vivek Sharma, MD, FRCA, ${ }^{a}$ Vivek Rao, MD, PhD, FRCSC, FACS, ${ }^{b}$ Cedric Manlhiot, PhD, \\ Audrey Boruvka, PhD, ${ }^{\mathrm{c}}$ Stephen Fremes, MD, FRCSC, ${ }^{\mathrm{d}}$ and Marcin Wąsowicz, MD, PhD, FRCPC ${ }^{\mathrm{a}}$
}

\begin{abstract}
Objectives: Prolonged mechanical ventilation after cardiac surgery imposes a significant burden on the patient in terms of morbidity as well as a financial burden on the hospital. We undertook a retrospective analysis of 2 prospectively collected databases developed in tertiary cardiac care centers to derive and validate a risk index predicting prolonged mechanical ventilation after cardiac surgery.

Methods: We studied a retrospective cohort of 32,045 patients undergoing cardiac surgery in 2 hospitals in Toronto, Canada. The development cohort consisted of 21,661 patients at Toronto General Hospital. Data Sunnybrook Health Sciences Centre, Toronto, Canada, with 10,384 patients, served as an institutional validation cohort. We operationally characterized prolonged mechanical ventilation as the duration from surgery completion to extubation exceeding 48 hours.

Results: Prolonged postoperative mechanical ventilation rates in the development and validation cohort were $6 \%$ and $7 \%$, respectively. Multivariable regression in the development cohort showed that the following factors were strong predictors of prolonged mechanical ventilation after cardiac surgery: previous cardiac surgery, lower left ventricular ejection fraction, shock, surgery involving repair of congenital heart disease, and cardiopulmonary bypass time. The intraoperative multivariable model retained good discrimination in the validation cohort, achieving a c statistic of 0.787 .
\end{abstract}

Conclusions: Prolonged mechanical ventilation after cardiac surgery can be accurately predicted by readily available pre- and intraoperative information. (J Thorac Cardiovasc Surg 2017;153:108-15)

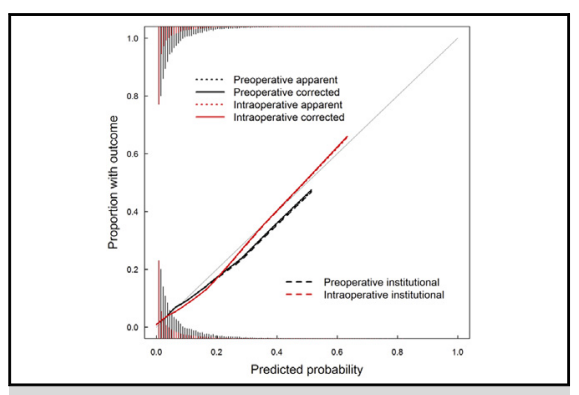

The total duration of mechanical ventilation model calibration.

Central Message

A risk index derived and validated in 32,045 patients can predict prolonged mechanical ventilation after cardiac surgery.

\section{Perspective}

Our study provides a risk index derived in 21,661 patients at Toronto General Hospital, Canada, and validated in 10,384 patients at Sunnybrook Hospital, Canada, to predict prolonged mechanical ventilation after cardiac surgery. The risk index incorporates the use of easily identifiable and routinely recorded pre- and intraoperative variables to predict prolonged mechanical ventilation after cardiac surgery.

See Editorial Commentary page 116.
Despite advances in the perioperative management of cardiac surgical patients, prolonged mechanical ventilation continues to be a significant postoperative problem with a

From the ${ }^{\mathrm{a}}$ Department of Anesthesia and Pain Management, Toronto General Hospital; ${ }^{b}$ Department of Surgery, Peter Munk Cardiac Centre, University Health Network; ${ }^{\mathrm{c}}$ Cardiovascular Data Management Centre, University of Toronto; and ${ }^{\mathrm{d}}$ Division of Cardiac Surgery, Schulich Heart Centre, Sunnybrook Health Sciences Centre, Toronto, Ontario, Canada.

Received for publication Feb 1, 2016; revisions received May 7, 2016; accepted for publication Aug 19, 2016; available ahead of print Sept 21, 2016.

Address for reprints: Vivek Sharma, MD, FRCA, Department of Anesthesia and Pain Management, Toronto General Hospital, 200 Elizabeth Street, 3EN-460, Ontario, Toronto, Canada M5G 2C4 (E-mail: docvvs@yahoo.co.in).

$0022-5223 / \$ 36.00$

Copyright (c) 2016 by The American Association for Thoracic Surgery

http://dx.doi.org/10.1016/j.jtcvs.2016.08.020 reported incidence of up to $22 \%$ depending on the threshold used to define prolonged mechanical ventilation. ${ }^{1-6}$ Prolonged mechanical ventilation after cardiac surgery imposes a significant burden on the patient in terms of morbidity as well as a financial burden on the hospital.

Scanning this QR code will take you to the article title page. 


\section{Abbreviations and Acronyms \\ $\mathrm{CPB}=$ cardiopulmonary bypass \\ ICU $=$ intensive care unit}

Furthermore, the mortality in the group of patients requiring prolonged mechanical ventilation can exceed $40 \% .{ }^{6}$ Hence, the development of a reliable prediction model to assist early identification (and treatment) of this problem is paramount.

A risk index that incorporates pre- and intraoperative factors that can accurately predict prolonged mechanical ventilation after cardiac surgery will improve clinical management and decision making in the perioperative milieu. In addition, estimation of risk of prolonged mechanical ventilation could assist in better preoperative counselling and informed decision making. It could also help the intensive care unit (ICU) in allocation of postoperative care resources and provide them with a guide to the estimated length of stay.

To facilitate widespread use, the predictive index should use contemporary perioperative characteristics and easily identifiable risk factors. The dataset used to derive the risk index should be a heterogeneous case mix thus allowing applicability to other centers. More importantly, the derived risk index should be externally validated in another heterogeneous albeit contemporary case mix. Finally, the risk index should be simple, easy to use, and allow a graded estimation of risk of prolonged mechanical ventilation.

Although several studies have identified predictors of prolonged mechanical ventilation after cardiac surgery, these studies are limited by sample size, complex scoring systems, homogeneity of population, and most importantly the lack of a validation cohort separate from model development. ${ }^{1-6,8-14}$

In view of these limitations, we undertook a retrospective analysis of 2 prospectively collected databases developed in tertiary cardiac care centers to derive and validate a risk index predicting prolonged mechanical ventilation after cardiac surgery.

\section{METHODS}

After institutional Research Ethical Board approval, perioperative data on patients undergoing cardiac surgery at Toronto General Hospital (Toronto, Ontario, Canada) and Sunnybrook Health Sciences Centre (Toronto, Ontario, Canada) were retrospectively analyzed from the prospectively collected hospital databases. The derivation and accuracy of these databases have been previously described. ${ }^{15}$

\section{Patient Population}

All adult patients (age $>18$ years) undergoing cardiac surgery with cardiopulmonary bypass (CPB) from January 2000 to April 2012 were included in this study. Patients who did not have a reported duration of mechanical ventilation, those who underwent advanced heart failure therapy, such as ventricular assist device insertion or heart transplantation, and patients who did not survive until 48 hours after surgery were excluded from this analysis. The cohort at Toronto General Hospital was used as the derivation cohort. Patients at Sunnybrook Health Sciences Centre with similar demographics and exclusion criteria to the derivation cohort formed the validation cohort for this study. The derived risk index was validated on the internal and external cohorts from Toronto General Hospital and Sunnybrook Health Sciences Centre, respectively.

\section{Definition of Outcome Variables}

Prolonged mechanical ventilation was defined as duration of postoperative mechanical ventilation exceeding 48 hours. This included patients who had been continuously ventilated for 48 postoperative hours and those who were extubated and subsequently reintubated resulting in a cumulative duration of mechanical ventilation in excess of 48 hours. We also examined total duration of mechanical ventilation, from operation to extubation, as an alternative outcome for prediction.

\section{ICU Management}

All patients were admitted to the cardiac ICU after cardiac surgery. Postoperative weaning from mechanical ventilation followed standard institutional protocols at both centers. Patients were considered to be eligible for extubation if they had achieved hemodynamic stability, normothermia (tympanic temperature $>36^{\circ} \mathrm{C}$ ), adequate oxygenation and ventilation indices on arterial blood gas samples, chest drainage of less than $100 \mathrm{~mL} /$ hour, normal neurologic findings such as alertness, orientation, and the ability to move all 4 limbs and obey commands on assessment following a decrease in the level of postoperative sedation. The critical care physician in charge of the cardiac surgical ICU was responsible for the final decision to extubate the patient after a successful trial of spontaneous ventilation and confirmation of normal neurologic findings. Similarly, the decision to reintubate the patient was at the discretion of the attending intensivist responsible for the respective cardiac ICU.

\section{Statistical Analysis}

Predictor variables were prespecified on the basis of clinical judgement, literature review, and availability in both the development and validation cohorts. To incorporate data from approximately $5 \%$ of the patients in the development cohort with missing predictor values, we carried out model development using multiply imputed data via chained equations. ${ }^{16}$ Logistic regression analysis was used to construct a prediction model for the binary outcome of prolonged mechanical ventilation outcome; this variable was available in all but 3 patients. For predicting total duration of mechanical ventilation, we considered a stratified Cox model, ${ }^{17,18}$ specific to the reason for extubation; either due to the aforementioned weaning protocol or terminal extubation, operationally defined as extubation occurring within 3 days of death. This approach enables both the prediction of time, rather than postoperative duration exceeding 48 hours, and makes the distinction between these 2 very different reasons for extubation. Model development for each outcome was carried out in 2 stages, with only preoperative characteristics and both pre- and intraoperative information.

Each model was internally validated on 100 bootstrap replications to assess overoptimism in regression coefficients and performance measures. Predictions under each model were performed on patients from the validation cohort with complete data. Model performance was assessed using the c statistic, R-squared value, and calibration curves. ${ }^{19}$

\section{RESULTS}

Ventilation times were missing for 7 Toronto General Hospital patients. A further $94(0.4 \%)$ patients had unknown postoperative ventilation time. For prolonged mechanical ventilation, all of these cases were excluded 
TABLE 1. Development and validation cohorts: patient and surgical characteristics

\begin{tabular}{|c|c|c|c|c|c|}
\hline \multirow[b]{2}{*}{ Variable } & \multicolumn{2}{|c|}{ Development $(N=21,654)$} & \multicolumn{2}{|c|}{ Validation $(N=10,384)$} & \multirow[b]{2}{*}{$P$ value } \\
\hline & $\mathbf{N}$ & & $\mathbf{N}$ & & \\
\hline Age (y) & & $65(37-80)$ & & $67(47-81)$ & $<.001$ \\
\hline Sex & & & & & $<.001$ \\
\hline Male & & $15,439(71.3)$ & & 7851 (75.6) & \\
\hline Female & & $6215(28.7)$ & & $2533(24.4)$ & \\
\hline Body mass index $\left(\mathrm{kg} / \mathrm{m}^{2}\right)$ & 21,619 & $27(21-37)$ & 10,315 & $27(21-37)$ & .91 \\
\hline Emergent surgery & 21,651 & $20,048(92.6)$ & 10,368 & $5557(53.6)$ & $<.001$ \\
\hline Year of operation & & & & & $<.001$ \\
\hline 2000-2004 & & $10,249(47.3)$ & & $5432(52.3)$ & \\
\hline $2005-2008$ & & $6219(28.7)$ & & $3070(29.6)$ & \\
\hline 2009-2012 & & $5186(23.9)$ & & $1882(18.1)$ & \\
\hline Any previous cardiac surgery & & $2045(9.4)$ & & $204(2.0)$ & $<.001$ \\
\hline Acute coronary insufficiency & 21,638 & $3231(14.9)$ & 10,348 & $3761(36.3)$ & $<.001$ \\
\hline Recent myocardial infarction & 21,647 & $3044(14.1)$ & & $1245(12.0)$ & $<.001$ \\
\hline NYHA classification & 20,767 & & 10,320 & & $<.001$ \\
\hline Class I & & $3180(15.3)$ & & $371(3.6)$ & \\
\hline Class II & & 4345 (20.9) & & 2928 (28.4) & \\
\hline Class III & & $6500(31.3)$ & & $2677(25.9)$ & \\
\hline Class IV & & $6742(32.5)$ & & $4344(42.1)$ & \\
\hline LVEF (\%) & 21,613 & & 9441 & & $<.001$ \\
\hline $40+$ & & $18,066(83.6)$ & & 7546 (79.9) & \\
\hline $20-39$ & & $3011(13.9)$ & & $1557(16.5)$ & \\
\hline$<20$ & & $536(2.5)$ & & $338(3.6)$ & \\
\hline Insulin-dependent diabetes mellitus & & $1305(6.0)$ & 10,364 & $622(6.0)$ & .94 \\
\hline Medically treated hypertension & 21,652 & $13,065(60.3)$ & 10,364 & $6250(60.3)$ & .95 \\
\hline Current smoker & 21,595 & $2774(12.8)$ & 10,363 & $1571(15.2)$ & $<.001$ \\
\hline Severe COPD & 21,653 & $883(4.1)$ & 10,360 & $683(6.6)$ & $<.001$ \\
\hline Previous stroke or TIA & 21,647 & $2009(9.3)$ & 10,364 & $775(7.5)$ & $<.001$ \\
\hline PVD or carotid stenosis $>70 \%$ & 21,653 & $2971(13.7)$ & 10,362 & $1290(12.4)$ & .002 \\
\hline Creatinine clearance (mL/min) & 21,609 & $81(38-145)$ & 10,201 & $81(38-143)$ & .134 \\
\hline Preoperative atrial fibrillation & & $1764(8.1)$ & & $933(9.0)$ & .012 \\
\hline $\mathrm{CHF}$ & 21,653 & $5089(23.5)$ & 10,362 & $1079(10.4)$ & $<.001$ \\
\hline Shock & 21,653 & $322(1.5)$ & 10,364 & $74(0.7)$ & $<.001$ \\
\hline Preoperative IABP & 21,651 & $439(2.0)$ & & $222(2.1)$ & .53 \\
\hline Valvular disease & & $8292(38.3)$ & 10,379 & $2753(26.5)$ & $<.001$ \\
\hline Total no. of diseased arterial systems & & & 10,383 & & $<.001$ \\
\hline 0 & & $6737(31.1)$ & & $1885(18.2)$ & \\
\hline 1 & & $1317(6.1)$ & & $661(6.4)$ & \\
\hline 2 & & $2882(13.3)$ & & $2118(20.4)$ & \\
\hline 3 & & $10,718(49.5)$ & & $5719(55.1)$ & \\
\hline Valve surgery & & $8821(40.7)$ & & $2631(25.3)$ & $<.001$ \\
\hline Repair of congenital defect & & $1338(6.2)$ & & $83(0.8)$ & $<.001$ \\
\hline Ascending aorta replaced & 21,617 & $2208(10.2)$ & & $587(5.7)$ & $<.001$ \\
\hline CPB time $(\min )$ & 21,648 & $95(52-179)$ & & $114(61-217)$ & $<.001$ \\
\hline Circulatory arrest & 21,642 & $856(4.0)$ & & $452(4.3)$ & .097 \\
\hline Intraoperative IABP & 21,651 & $416(1.9)$ & & $390(3.8)$ & $<.001$ \\
\hline Prolonged ventilation & 21,560 & $1345(6.2)$ & 10,330 & $759(7.3)$ & $<.001$ \\
\hline Total ventilation time $(\mathrm{h})$ & & $9.25(4.78-71.12)$ & 10,361 & $12.67(7.08-94.40)$ & $<.001$ \\
\hline Status at ventilation time & & & & & $<.001$ \\
\hline Censored & & $94(0.4)$ & & $53(0.5)$ & \\
\hline Extubated & & $21,212(98.0)$ & & $10,091(97.2)$ & \\
\hline Terminally extubated & & $348(1.6)$ & & $240(2.3)$ & \\
\hline
\end{tabular}

NYHA, New York Heart Association; $L V E F$, left ventricular ejection fraction; COPD, chronic obstructive pulmonary disease; TIA, transient ischemic attack; $P V D$, peripheral vascular disease; $C H F$, congestive heart failure; $I A B P$, intra-aortic balloon pump; $C P B$, cardiopulmonary bypass. 
TABLE 2. Multivariable logistic regression model odds ratios for prolonged postoperative mechanical ventilation, at the preoperative and intraoperative stages

\begin{tabular}{|c|c|c|c|c|}
\hline \multirow[b]{2}{*}{ Variable } & \multicolumn{2}{|c|}{ Preoperative } & \multicolumn{2}{|c|}{ Intraoperative } \\
\hline & Odds ratio $(95 \% \mathrm{CI})$ & $P$ value & Odds ratio $(95 \% \mathrm{CI})$ & $P$ value \\
\hline Age (y), 55 vs 73 & $1.28(0.76-2.17)$ & .004 & $1.30(0.73-2.32)$ & .36 \\
\hline Sex, female vs male & $0.93(0.82-1.06)$ & .029 & $0.97(0.84-1.11)$ & .33 \\
\hline Year of operation, 2000-2004 vs 2005-2012 & $0.94(0.83-1.06)$ & $<.001$ & $0.96(0.84-1.09)$ & .031 \\
\hline Emergent surgery & $0.36(0.29-0.43)$ & .92 & $0.45(0.37-0.55)$ & .57 \\
\hline Body mass index $\left(\mathrm{kg} / \mathrm{m}^{2}\right), 24$ vs 31 & $1.35(0.45-4.07)$ & .28 & $1.32(0.46-3.79)$ & .63 \\
\hline Any previous cardiac surgery & $2.17(1.84-2.57)$ & $<.001$ & $1.31(1.08-1.58)$ & $<.001$ \\
\hline Acute coronary insufficiency & $1.18(0.98-1.43)$ & .28 & $1.31(1.07-1.61)$ & .50 \\
\hline Recent myocardial infarction & $0.98(0.81-1.18)$ & $<.001$ & $0.99(0.81-1.21)$ & .005 \\
\hline NYHA classification, III vs I-II & $1.16(0.97-1.39)$ & .002 & $1.08(0.89-1.30)$ & .96 \\
\hline NYHA classification, IV vs I-II & $1.41(1.17-1.69)$ & $<.001$ & $1.16(0.96-1.41)$ & .017 \\
\hline LVEF $(\%), 20-39$ vs $40+$ & $1.15(0.98-1.35)$ & $<.001$ & $0.97(0.82-1.16)$ & $<.001$ \\
\hline LVEF $(\%),<20$ vs $40+$ & $2.09(1.61-2.73)$ & .171 & $1.56(1.17-2.09)$ & $<.001$ \\
\hline IDDM & $1.14(0.92-1.42)$ & .088 & $1.13(0.89-1.43)$ & .010 \\
\hline Medically treated hypertension & $1.18(1.03-1.35)$ & .84 & $1.16(1.01-1.34)$ & .92 \\
\hline Current smoker & $1.08(0.90-1.29)$ & .093 & $1.07(0.88-1.30)$ & .44 \\
\hline Severe COPD & $1.66(1.32-2.08)$ & $<.001$ & $1.60(1.26-2.04)$ & .132 \\
\hline Previous stroke or TIA & $1.19(1.00-1.42)$ & .081 & $1.16(0.96-1.39)$ & .77 \\
\hline PVD or carotid stenosis $>70 \%$ & $1.47(1.26-1.72)$ & $<.001$ & $1.40(1.19-1.64)$ & .003 \\
\hline Preoperative atrial fibrillation & $1.22(1.02-1.47)$ & .020 & $1.16(0.95-1.41)$ & .039 \\
\hline Congestive heart failure & $1.66(1.44-1.93)$ & .43 & $1.71(1.46-1.99)$ & .48 \\
\hline Shock & $1.65(1.21-2.26)$ & $<.001$ & $1.39(1.00-1.95)$ & $<.001$ \\
\hline Preoperative IABP & $2.99(2.27-3.94)$ & .046 & $5.02(3.76-6.69)$ & .127 \\
\hline Creatinine clearance (mL/min), 61 vs 104 & $0.52(0.15-1.76)$ & .24 & $0.53(0.14-1.93)$ & .31 \\
\hline Valvular disease & $1.81(1.54-2.12)$ & $<.001$ & $0.71(0.50-1.01)$ & $<.001$ \\
\hline No. of diseased arterial systems, 0 vs 3 & $1.15(0.94-1.40)$ & $<.001$ & $0.81(0.65-1.01)$ & $<.001$ \\
\hline Valve surgery & & & $1.21(0.83-1.77)$ & .142 \\
\hline Repair of congenital defect & & & $1.33(1.03-1.72)$ & $<.001$ \\
\hline Ascending aorta replaced & & & $1.01(0.81-1.25)$ & .053 \\
\hline CPB time (min), 76 vs 120 & & & $1.78(0.68-4.63)$ & $<.001$ \\
\hline Circulatory arrest & & & $1.76(1.36-2.27)$ & .055 \\
\hline Intraoperative IABP & & & $9.01(7.11-11.42)$ & .057 \\
\hline
\end{tabular}

from model development. The 94 cases were censored when modeling the total duration of mechanical ventilation. Complete predictor and outcome information from Sunnybrook Health Sciences Centre was available for $89 \%$ of patients. This gave development and institutional validation cohorts of up to 21,654 and 9244 patients, respectively. Of these, $1345(6.2 \%)$ and $759(7.3 \%)$ patients experienced prolonged mechanical ventilation, respectively. The distribution of the preselected predictor variables and outcomes for the cohorts are summarized in Table 1 .

For the binary outcome of prolonged mechanical ventilation, multivariable logistic regression with multiply imputed data from the development cohort led to the identification of 8 to 10 strong predictors of prolonged ventilation; however, all preselected variables were retained in the model regardless of statistical significance (Table 2).
Internal validation showed little indication of overfitting, regardless of the outcome under prediction and stage, with the apparent performance measures and calibration curves similar to the corrected values (Figure 1). As one might expect, both the apparent and institutional performance improved with predictions made at the intraoperative stage, with respective c statistics (area under the receiver operating characteristic curve) of 0.840 and 0.787 .

In Cox regression analysis, most of the preselected variables appeared useful in predicting the total duration of mechanical ventilation, particularly for nonterminal extubations (Tables 3 and 4). Duration proved relatively difficult to predict with a high degree of discrimination. However, the Cox regression model performed reasonably well, with apparent and institutional c statistics at the intraoperative stage of 0.695 and 0.697 , respectively (Table 5). All calibration curves showed a strong linear 


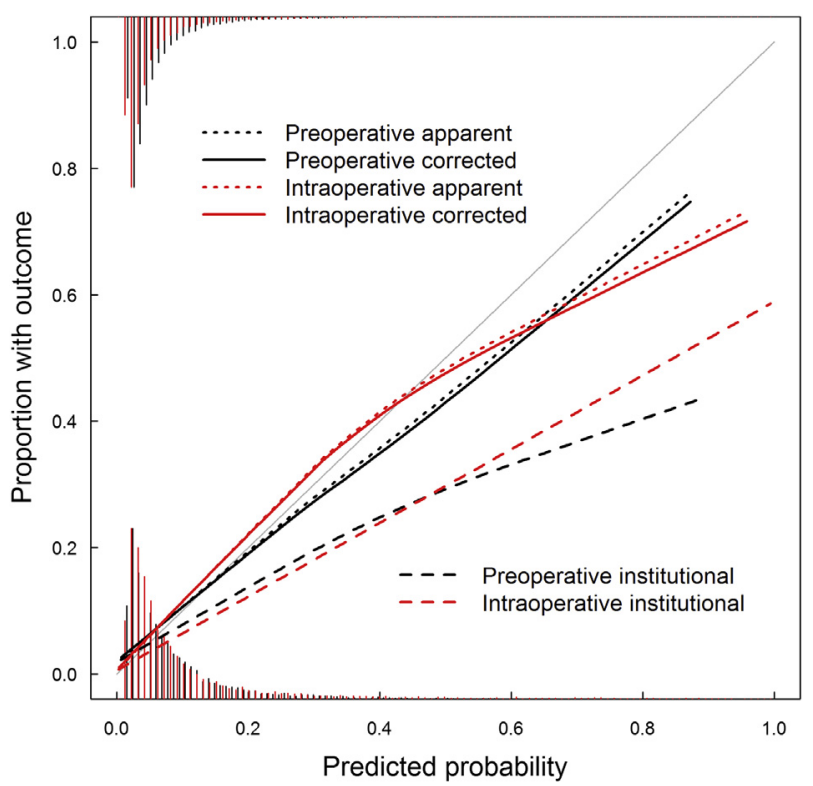

FIGURE 1. Prolonged postoperative mechanical ventilation model calibration.

trend, particularly among patients more likely to have longer duration (Figure 2).

\section{DISCUSSION}

This study provides a derived and validated risk index to predict prolonged mechanical ventilation after cardiac surgery. Our risk index incorporates the use of 12 easily identifiable and routinely recorded pre- and intraoperative variables to predict prolonged mechanical ventilation after cardiac surgery. The principal strength of our risk index lies in the successful external validation of most of the internally derived risk factors to predict prolonged ventilation in cardiac surgical patients.

Prediction of prolonged mechanical ventilation after cardiac surgery has been the focus of other studies, and similar or closely related risk factors have been identified by these studies. ${ }^{1-14}$ However, none of these studies have validated their respective risk-prediction models in a large validation cohort.

The prevalence of prolonged mechanical ventilation after cardiac surgery and the morbidity and mortality associated with it differs with the threshold used to define prolonged mechanical ventilation. ${ }^{1-14}$ The prevalence of prolonged mechanical ventilation in our study of $6.2 \%$ and of $7.3 \%$ in the derivation and external validation cohorts, respectively, is in agreement with other reports. We chose a threshold of 48 hours to define prolonged mechanical ventilation for several reasons. The Society of Thoracic Surgeons identifies prolonged mechanical ventilation as a total duration of mechanical ventilation $>24$ hours after exit from the operating room in patients undergoing isolated coronary artery bypass grafting only. ${ }^{20}$ The risk profile of cardiac surgical patients has changed over the past decades, with a higher proportion of elderly patients having multiple comorbidities being referred for more complex cardiac surgical procedures. ${ }^{10}$ Such patients may not be ideally suited for early extubation and our 48-hour cutoff allows for integration of this subpopulation in the analysis. The 48-hour threshold also helps us to overcome factors such as slow recovery from sedation, transient or minor complications, logistical issues such as staffing, and adherence to local extubation policies and protocols, which could contribute to prolonged mechanical ventilation. Furthermore, we believe that, due to the complexity of cases performed at our hospitals, a 24-hour threshold to define prolonged mechanical ventilation would overestimate the prevalence of this complication. ${ }^{21-25}$

That said, the selection of any threshold is somewhat arbitrary and makes no distinction between extubation due to protocol weaning and terminal extubation. Our results show that the same pre- and intraoperative characteristics are also able to reasonably predict the total duration of mechanical ventilation, regardless of the subsequent reason for extubation.

Our analysis consistently identified previous cardiac surgery, cardiogenic shock, and prolonged CPB time as the major predictors of prolonged mechanical ventilation in both the derivation and validation cohorts. The deleterious effects of prolonged CPB are multiple and include the potential of inducing cardiac dysfunction, initiation of a systemic inflammatory response thus leading to activation of mediators, and alteration of normal physiologic homeostasis, which leads to increased capillary permeability including pulmonary circulation. Disruption of the normal endothelial barrier in the pulmonary circulation results in extravasation of lung water, thereby inducing a mild pulmonary edema, which may in turn contribute to respiratory failure and prolonged mechanical ventilation after cardiac surgery. ${ }^{26}$

The preoperative presence of an intraoperative balloon pump implies critical coronary vascular disease needing emergent cardiac surgical intervention. This setting offers limited opportunity for preoperative optimization and may be responsible for the higher morbidity of prolonged mechanical ventilation as shown in our study. Finally, patients with chronic renal failure have other associated comorbidities, such as peripheral vascular disease, atherosclerosis, diabetes, and hypertension, which contribute to a greater systemic burden of cardiac surgery.

There are multiple implications of the findings presented in our study. They are significant for both clinical management and future research on respiratory complications in cardiac surgical patients. Potentially, they can lead to several changes in the perioperative management of cardiac surgical patients such as better preoptimization 
TABLE 3. Multivariable Cox regression model hazard ratios for total duration of mechanical ventilation at the preoperative stage

\begin{tabular}{|c|c|c|c|c|}
\hline \multirow[b]{2}{*}{ Variable } & \multicolumn{2}{|c|}{ Nonterminal extubation } & \multicolumn{2}{|c|}{ Terminal extubation } \\
\hline & Hazard ratio $(95 \%$ CI $)$ & $P$ value & Hazard ratio $(95 \% \mathrm{CI})$ & $P$ value \\
\hline Age $(y)$, linear & $0.99(0.99-1.00)$ & $<.001$ & $1.00(0.99-1.01)$ & .98 \\
\hline Age (y), nonlinear & & $<.001$ & & $<.001$ \\
\hline Sex & $0.94(0.91-0.98)$ & .001 & $1.40(1.11-1.77)$ & .005 \\
\hline Year of operation & $1.28(1.24-1.32)$ & $<.001$ & $1.36(1.08-1.71)$ & .009 \\
\hline Emergent surgery & $1.55(1.45-1.65)$ & $<.001$ & $0.67(0.48-0.94)$ & .020 \\
\hline Body mass index $\left(\mathrm{kg} / \mathrm{m}^{2}\right)$, linear & $0.99(0.98-0.99)$ & $<.001$ & $1.01(0.98-1.03)$ & .61 \\
\hline Body mass index $\left(\mathrm{kg} / \mathrm{m}^{2}\right)$, nonlinear & & $<.001$ & & .44 \\
\hline Any previous cardiac surgery & $0.58(0.55-0.61)$ & $<.001$ & $1.86(1.35-2.57)$ & $<.001$ \\
\hline Acute coronary insufficiency & $0.98(0.93-1.02)$ & .32 & $1.11(0.79-1.55)$ & .56 \\
\hline Recent myocardial infarction & $1.03(0.98-1.08)$ & .27 & $0.91(0.64-1.29)$ & .60 \\
\hline NYHA classification, III vs I-II & $0.91(0.87-0.94)$ & $<.001$ & $1.65(1.09-2.49)$ & .018 \\
\hline NYHA classification, IV vs I-II & $0.83(0.80-0.87)$ & $<.001$ & $2.14(1.41-3.24)$ & $<.001$ \\
\hline LVEF (\%), 20-39 vs $40+$ & $0.88(0.85-0.92)$ & $<.001$ & $1.35(1.01-1.79)$ & .043 \\
\hline $\operatorname{LVEF}(\%),<20$ vs $40+$ & $0.66(0.61-0.72)$ & $<.001$ & $2.57(1.72-3.85)$ & $<.001$ \\
\hline IDDM & $0.87(0.82-0.93)$ & $<.001$ & $0.96(0.65-1.41)$ & .83 \\
\hline Medically treated hypertension & $0.94(0.91-0.97)$ & $<.001$ & $1.08(0.84-1.40)$ & .55 \\
\hline Current smoker & $0.95(0.91-0.99)$ & .022 & $1.22(0.88-1.70)$ & .24 \\
\hline Severe COPD & $0.82(0.76-0.89)$ & $<.001$ & $1.09(0.72-1.66)$ & .68 \\
\hline Previous stroke or TIA & $0.91(0.87-0.96)$ & $<.001$ & $1.10(0.80-1.51)$ & .55 \\
\hline PVD or carotid stenosis $>70 \%$ & $0.88(0.85-0.92)$ & $<.001$ & $1.36(1.02-1.81)$ & .035 \\
\hline Preoperative atrial fibrillation & $0.88(0.83-0.92)$ & $<.001$ & $1.00(0.71-1.39)$ & .98 \\
\hline $\mathrm{CHF}$ & $0.89(0.86-0.93)$ & $<.001$ & $1.14(0.85-1.52)$ & .37 \\
\hline Shock & $0.72(0.64-0.81)$ & $<.001$ & $1.19(0.78-1.82)$ & .42 \\
\hline Preoperative IABP & $0.60(0.55-0.66)$ & $<.001$ & $0.71(0.45-1.10)$ & .126 \\
\hline Creatinine clearance $(\mathrm{mL} / \mathrm{min})$, linear & $1.00(1.00-1.01)$ & $<.001$ & $0.99(0.98-1.00)$ & .012 \\
\hline Creatinine clearance $(\mathrm{mL} / \mathrm{min})$, nonlinear & & $<.001$ & & $<.001$ \\
\hline Valvular disease & $0.73(0.70-0.76)$ & $<.001$ & $0.93(0.69-1.25)$ & .61 \\
\hline No. of diseased arterial systems & $0.93(0.91-0.94)$ & $<.001$ & $0.94(0.83-1.06)$ & .28 \\
\hline
\end{tabular}

Regression coefficients for age, body mass index, creatinine clearance and bypass time are spline based, but are summarized as linear and overall linear terms. $C I$, Confidence interval; NYHA, New York Heart Association; $L V E F$, left ventricular ejection fraction; IDDM, insulin-dependent diabetes mellitus; COPD, chronic obstructive pulmonary disease; TIA, transient ischemic attack; $P V D$, peripheral vascular disease; $C H F$, congestive heart failure; IABP, intra-aortic balloon pump.

of patients with high New York Heart Association scores, prediction of ICU workload and subsequent cost incurred by the hospital, the ability to rationalize and tailor postoperative mechanical ventilation strategy for high-risk patients, and finally better preoperative discussion and consent making about the deemed risk and benefit of the proposed surgical procedure. Clinicians and researchers need to be aware that the risk index does not provide absolute risk values for prolonged mechanical ventilation. However, estimation of absolute risk is infrequent and most clinicians prefer to classify patients as low, intermediate, and high risk to simplify the risk stratification process.

Our study has several limitations. Similar to other retrospective observational studies and risk-prediction models, some conclusions of this study may be limited in their application and risk models can only apply variables that have been collected. There is no consensus on the accepted definition of prolonged mechanical ventilation after cardiac surgery, while other investigators have used a wide range of time frames within a range of 8 hours to 14 days to define prolonged mechanical ventilation following cardiac surgery. Three risk factors in the derivation model failed to achieve statistical significance in the external validation model, and the possible reasons for this have been outlined earlier. Our study was not designed to establish an association between prolonged mechanical ventilation and postoperative outcomes such as long-term survival, mortality, and in-hospital morbidity because others have already studied these complications. We do not have detailed data on the perioperative use of inotropic and vasoactive agents because the use of these agents is predominantly protocolized and institution specific and may confound the results.

In summary, we have described a derived and validated risk index to predict prolonged mechanical ventilation after cardiac surgery using pre- and intraoperative variables that may be routinely collected in most cardiac surgical centers. The heterogeneity of 
TABLE 4. Multivariable Cox regression model hazard ratios for total duration of mechanical ventilation at the intraoperative stage

\begin{tabular}{|c|c|c|c|c|}
\hline \multirow[b]{2}{*}{ Variable } & \multicolumn{2}{|c|}{ Nonterminal extubation } & \multicolumn{2}{|c|}{ Terminal extubation } \\
\hline & Hazard ratio $(95 \%$ CI $)$ & $P$ value & Hazard ratio $(95 \%$ CI $)$ & $P$ value \\
\hline Age $(y)$, linear & $0.99(0.99-0.99)$ & $<.001$ & $1.01(0.99-1.02)$ & .31 \\
\hline Age $(y)$, nonlinear & & $<.001$ & & $<.001$ \\
\hline Sex & $0.92(0.89-0.96)$ & $<.001$ & $1.48(1.16-1.89)$ & .002 \\
\hline Year of operation & $1.31(1.27-1.35)$ & $<.001$ & $1.33(1.05-1.69)$ & .018 \\
\hline Emergent surgery & $1.40(1.31-1.50)$ & $<.001$ & $0.72(0.52-0.99)$ & .045 \\
\hline Body mass index $\left(\mathrm{kg} / \mathrm{m}^{2}\right)$, linear & $0.99(0.99-1.00)$ & $<.001$ & $1.01(0.99-1.03)$ & .54 \\
\hline Body mass index $\left(\mathrm{kg} / \mathrm{m}^{2}\right)$, nonlinear & & $<.001$ & & .005 \\
\hline Any previous cardiac surgery & $0.77(0.73-0.82)$ & $<.001$ & $1.52(1.08-2.13)$ & .016 \\
\hline Acute coronary insufficiency & $0.91(0.87-0.96)$ & .001 & $1.14(0.80-1.63)$ & .47 \\
\hline Recent myocardial infarction & $1.03(0.98-1.08)$ & .28 & $0.94(0.66-1.35)$ & .76 \\
\hline NYHA classification, III vs I-II & $0.94(0.90-0.98)$ & .002 & $1.45(0.95-2.23)$ & .086 \\
\hline NYHA classification, IV vs I-II & $0.88(0.84-0.92)$ & $<.001$ & $1.90(1.24-2.90)$ & .003 \\
\hline LVEF (\%), 20-39 vs 40+ & $0.92(0.88-0.96)$ & $<.001$ & $1.33(0.98-1.80)$ & .071 \\
\hline $\operatorname{LVEF}(\%),<20$ vs $40+$ & $0.74(0.67-0.82)$ & $<.001$ & $2.77(1.84-4.16)$ & $<.001$ \\
\hline IDDM & $0.87(0.81-0.93)$ & $<.001$ & $1.01(0.68-1.51)$ & .96 \\
\hline Medically treated hypertension & $0.95(0.91-0.98)$ & .001 & $1.15(0.88-1.51)$ & .31 \\
\hline Current smoker & $0.94(0.90-0.99)$ & .016 & $1.29(0.90-1.84)$ & .164 \\
\hline Severe COPD & $0.84(0.77-0.91)$ & $<.001$ & $1.09(0.71-1.68)$ & .69 \\
\hline Previous stroke or TIA & $0.93(0.88-0.98)$ & .011 & $1.07(0.78-1.47)$ & .68 \\
\hline PVD or carotid stenosis $>70 \%$ & $0.89(0.85-0.93)$ & $<.001$ & $1.36(1.02-1.81)$ & .037 \\
\hline Preoperative atrial fibrillation & $0.91(0.86-0.96)$ & $<.001$ & $0.85(0.60-1.21)$ & .36 \\
\hline $\mathrm{CHF}$ & $0.88(0.85-0.92)$ & $<.001$ & $1.12(0.84-1.48)$ & .45 \\
\hline Shock & $0.79(0.70-0.89)$ & $<.001$ & $0.96(0.62-1.48)$ & .84 \\
\hline Preoperative IABP & $0.48(0.44-0.53)$ & $<.001$ & $1.11(0.70-1.75)$ & .66 \\
\hline Creatinine clearance $(\mathrm{mL} / \mathrm{min})$, linear & $1.01(1.01-1.01)$ & $<.001$ & $0.99(0.99-1.00)$ & .002 \\
\hline Creatinine clearance $(\mathrm{mL} / \mathrm{min})$, nonlinear & & $<.001$ & & $<.001$ \\
\hline Valvular disease & $1.13(1.00-1.28)$ & .059 & $0.54(0.32-0.91)$ & .021 \\
\hline No. of diseased arterial systems & $0.98(0.96-1.00)$ & .047 & $0.88(0.77-1.00)$ & .056 \\
\hline Valve surgery & $0.92(0.81-1.05)$ & .23 & $1.22(0.69-2.16)$ & .49 \\
\hline Repair of congenital defect & $0.88(0.81-0.95)$ & .001 & $0.79(0.48-1.29)$ & .34 \\
\hline Ascending aorta replaced & $0.96(0.90-1.02)$ & .173 & $0.82(0.54-1.25)$ & .36 \\
\hline CPB time (min), linear & $0.99(0.99-0.99)$ & $<.001$ & $1.01(1.00-1.01)$ & .017 \\
\hline CPB time (min), nonlinear & & $<.001$ & & $<.001$ \\
\hline Circulatory arrest & $0.74(0.68-0.80)$ & $<.001$ & $1.55(1.02-2.36)$ & .042 \\
\hline Intraoperative IABP & $0.36(0.33-0.39)$ & $<.001$ & $2.04(1.45-2.86)$ & $<.001$ \\
\hline
\end{tabular}

Regression coefficients for age, body mass index, creatinine clearance and bypass time are spline based, but are summarized as linear and overall linear terms. $C I$, Confidence interval; NYHA, New York Heart Association; $L V E F$, left ventricular ejection fraction; IDDM, insulin-dependent diabetes mellitus; COPD, chronic obstructive pulmonary disease; TIA, transient ischemic attack; $P V D$, peripheral vascular disease; $C H F$, congestive heart failure; $I A B P$, intra-aortic balloon pump; $C P B$, cardiopulmonary bypass.

the patient population and the successful validation of most variables in an external cohort of cardiac surgical patients lend further credibility to our risk index. This risk index may help in preoperative optimization, risk stratification, consent and decision making, and postoperative financial and resource management in cardiac surgical patients. Further studies may wish to explore the impact of this or other similar risk indices on the perioperative medical, resource and cost management in cardiac surgical patients.

TABLE 5. Performance of the prolonged postoperative ventilation and time to extubation models, at the preoperative and intraoperative stages

\begin{tabular}{|c|c|c|c|c|c|c|}
\hline \multirow[b]{2}{*}{ Model performance metric } & \multicolumn{3}{|c|}{ Preoperative } & \multicolumn{3}{|c|}{ Intraoperative } \\
\hline & Apparent & Internal & Institutional & Apparent & Internal & Institutional \\
\hline Prolonged ventilation c statistic & 0.777 & 0.771 & 0.698 & 0.840 & 0.835 & 0.787 \\
\hline $\mathrm{R}^{2}$ & 0.171 & 0.164 & 0.060 & 0.276 & 0.267 & 0.125 \\
\hline Time to extubation c statistic & 0.653 & 0.652 & 0.654 & 0.695 & 0.694 & 0.697 \\
\hline $\mathrm{R}^{2}$ & 0.148 & 0.144 & 0.141 & 0.247 & 0.243 & 0.240 \\
\hline
\end{tabular}




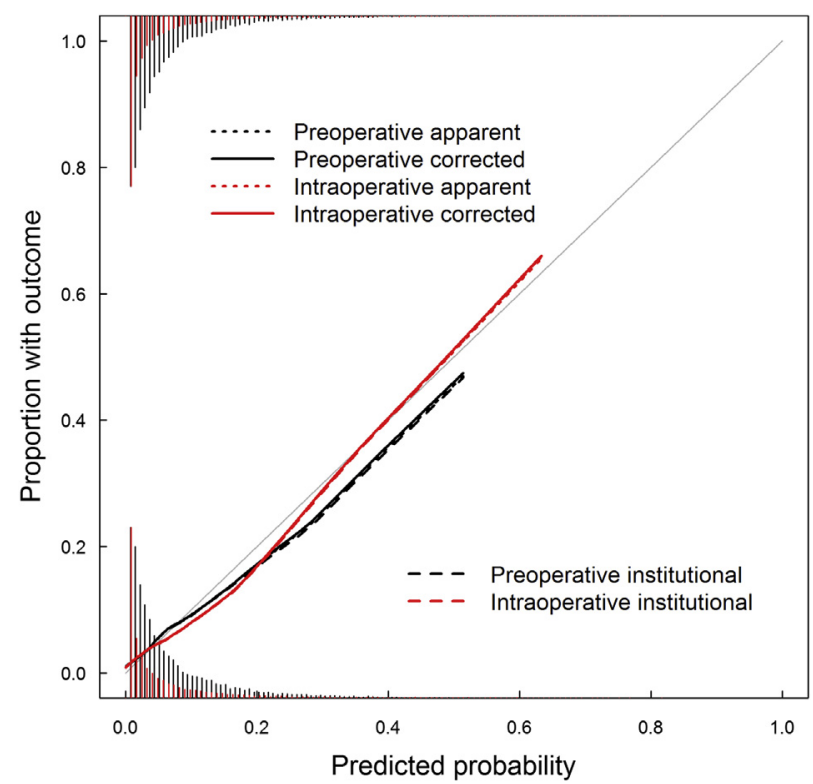

FIGURE 2. Total duration of mechanical ventilation model calibration. The outcome under prediction is duration lasting more than 48 hours.

\section{Conflict of Interest Statement}

Authors have nothing to disclose with regard to commercial support.

\section{References}

1. Kern H, Redlich U, Hotz H, von Heymann C, Grosse J, Konertz W, et al. Risk factors for prolonged ventilation after cardiac surgery using APACHE II, SAPS II, and TISS: comparison of three different models. Intensive Care Med. 2001;27:407-15.

2. Branca P, McGaw P, Light RW. Risk factors associated with prolonged mechanical ventilation following coronary artery bypass surgery. Chest. 2001; 119:537-46.

3. Rajakaruna C, Rogers CA, Angelini GD, Ascione R. Risk factors for and economic implications of prolonged ventilation after cardiac surgery. J Thorac Cardiovasc Surg. 2005;130:1270-7.

4. Reddy S, Grayson AD, Griffiths EM, Pullan DM, Rashid A. Logistic risk model for prolonged ventilation after adult cardiac surgery. Ann Thorac Surg. 2007;84: 528-36.

5. Thompson MJ, Elton RA, Mankad PA, Campanella C, Walker WS, Sang CT, et al. Prediction of requirement for, and outcome of, prolonged mechanical ventilation following cardiac surgery. Cardiovasc Surg. 1997;5:376-81.

6. LoCicero J III, McCann B, Massad M, Joob AW. Prolonged ventilatory support after open-heart surgery. Crit Care Med. 1992;20:990-2.

7. Cohen AJ, Katz MG, Frenkel G, Medalion B, Geva D, Schachner A. Morbid results of prolonged intubation after coronary artery bypass surgery. Chest. 2000; $118: 1724-31$
8. Murthy SC, Arroliga AC, Walts PA, Feng J, Yared J-P, Lytle BW, et al. Ventilator dependency after cardiovascular surgery. J Thorac Cardiovasc Surg. 2007;134: 484-90.

9. Canver CC, Chanda J. Intraoperative and postoperative risk factors for respiratory failure after coronary bypass. Ann Thorac Surg. 2003;75:853-8.

10. Filsoufi F, Rahmanian PB, Castillo JG, Chikwe J, Adams DH. Predictors and early and late outcomes of respiratory failure in contemporary cardiac surgery. Chest. 2008;133:713-21.

11. Saleh HZ, Shaw M, Al-Rawi O, Yates J, Pullan DM, Chalmers JA, et al Outcomes and predictors of prolonged ventilation in patients undergoing elective coronary surgery. Interact Cardiovasc Thorac Surg. 2012;15:51-6.

12. Widyastuti Y, Stenseth R, Pleym H, Wahba A, Videm V. Pre-operative and intraoperative determinants for prolonged ventilation following adult cardiac surgery. Acta Anaesthesiol Scand. 2012;56:190-9.

13. Cislaghi F, Condemi AM, Corona A. Predictors of prolonged mechanical ventilation in a cohort of 5123 cardiac surgical patients. Eur J Anaesthesiol. 2009;26:396-403

14. Trouillet JL, Combes A, Vaissier E, Luyt CE, Ouattara A, Pavie A, et al Prolonged mechanical ventilation after cardiac surgery: outcomes and predictors. J Thorac Cardiovasc Surg. 2009;138:948-53.

15. Karkouti K, Beattie WS, Wijeysundera DN, Rao V, Chan C, Dattilo KM, et al. Hemodilution during cardiopulmonary bypass is an independent risk factor for acute renal failure in adult cardiac surgery. J Thorac Cardiovasc Surg. 2005; 129:391-400

16. van Buuren S, Groothuis-Oudshoorn K. mice: multivariate imputation by chained equations in R. J Stat Softw. 2011;45:1-67.

17. Therneau T. A package for survival analysis in S. R package version 2.38 Available at: http://CRAN.R-project.org/package=survival. Accessed April 14, 2016

18. Therneau TM, Grambsch PM. The Cox Model. In: Therneau TM, Grambsch PM, eds. Modeling Survival Data: Extending the Cox Model. 1st ed. New York: Springer-Verlag; 2000:39-77.

19. Harrell FE Jr. rms: regression modeling strategies. R package version 4.4-2. 2016. Available at: https://CRAN.R-project.org/package $=$ rms. Accessed April 15,2015 .

20. The Society of Thoracic Surgeons. Available at: http://www.sts.org/quality-researchpatient-safety/quality/quality-performance-measures. Accessed December 12, 2015.

21. David TE, Feindel CM, David CM, Manlhiot C. A quarter of a century experi ence with aortic valve-sparing operations. J Thorac Cardiovasc Surg. 2014 148:872-80.

22. Garrido-Olivares L, Maganti M, Armstrong S, David TE. Clinical outcomes of aortic root replacement after previous aortic root replacement. J Thorac Cardiovasc Surg. 2013;146:611-5.

23. Sheikh AM, Elhenawy AM, Maganti M, Armstrong S, David TE, Feindel CM Outcomes of double valve surgery after infective endocarditis. J Thorac Cardiovasc Surg. 2009;138:69-75.

24. Maganti M, Rao V, Armstrong S, Feindel CM, Scully HE, David TE. Redo valvular surgery in elderly patients. Ann Thorac Surg. 2009;87:521-5.

25. David TE, Armstrong S, Maganti M, Ihlberg L. Clinical outcomes of combined aortic root replacement with mitral valve surgery. J Thorac Cardiovasc Surg. 2008:136:82-7.

26. Apostolakis E, Filos KS, Koletsis E, Dougenis D. Lung dysfunction following cardiopulmonary bypass. J Card Surg. 2010;25:47-55.

Key Words: prolonged mechanical ventilation, cardiac surgery, validated model 